\title{
Comparing the Efficacy of Three Minimally Invasive Techniques on Demineralized Dentin in Primary Teeth and Evaluating Its Residual Dentin and Microhardness Levels: An In Vitro Study
}

\author{
Abinaya $\mathrm{R}^{1}$, Priya Nagar ${ }^{2}$, Pallavi Urs ${ }^{3}$, Janani J ${ }^{4}$, Smitha $\mathrm{S}^{5}$
}

\begin{abstract}
Aim: This study aims to compare the caries removal efficacy of three minimally invasive techniques and to analyze qualitatively under stereomicroscopy and quantitatively using Vickers hardness test.

Materials and methods: Thirty non-carious anterior primary teeth were selected and subjected to demineralization and the same was confirmed using RadioVisioGraphy (RVG). Samples were divided into three groups: Bromelain gel, smart bur, and atraumatic restorative technique (ART). Caries removal was carried out for a time period of 2 minutes. The remaining demineralized dentin was measured using stereomicroscopy. Random dentin blocks were prepared and a microhardness test was conducted.

Statistical analysis: Data were subjected to statistical analysis by one-way analysis of variance (ANOVA) test.

Results: Stereomicroscopic analysis revealed bromelain gel and smart burs to be superior to ART. Bromelain gel was found to have comparable microhardness levels as healthy dentin. Statistically significant $(p<0.001)$ results were obtained.

Conclusion: In terms of caries removal and microhardness, bromelain gel was highly efficient when compared to other groups.

Clinical significance: Fear and anxiety of children and parents about conventional drills led to the emerging trends of minimally invasive restorative dentistry. This research indicated the use of bromelain gel and smart bur in the process of caries removal and that bromelain was more efficient when compared to other groups.
\end{abstract}

Keywords: Bromelain, Chemomechanical caries removal, Minimally invasive techniques, Original research, Smart burs, Vickers microhardness. International Journal of Clinical Pediatric Dentistry (2020): 10.5005/jp-journals-10005-1815

\section{INTRODUCTION}

Dental caries is regarded as one of the most common chronic childhood diseases worldwide and is the second largest cause of tooth loss after periodontitis. The balance between demineralization and remineralization determines if caries progresses, stops, or reverses. A few individuals consider caries removal as an unpleasant procedure due to the usage of conventional drills. It causes severe trauma psychologically as it creates an unpleasant aura increasing the fear and anxiety of both parents and children due to which they deny the treatment. Also, some of the disadvantages of using conventional drills may include pain and need to use local anesthesia, trauma to the pulp due to pressure, thermal damage, and vibration, and most of the time overextended cavity preparations. ${ }^{1}$

In the early days, caries removal was performed according to G.V. Black's "extension for prevention". Over a period, due to the evolution in dentistry, the "minimally invasive" approach is trending in dentistry. This approach to treat dental caries detects, diagnoses, intercepts, and treats dental caries at the microscopic level. Minimally invasive techniques are comprised of laser-ablation, sono-abrasion, dental smart materials, atraumatic restorative technique (ART), and chemomechanical caries removal techniques (CMCR). ${ }^{2}$

Smart burs are made of a medical-grade polymer which is of polyamide resin type. They come in three different ISO sizes 010, 014 , and $018^{3}$ which can be used at 500 to $800 \mathrm{rpm}$ in a slow speed
${ }^{1-5}$ Department of Pedodontics and Preventive Dentistry, Krishnadevaraya College of Dental Sciences, Bengaluru, Karnataka, India

Corresponding Author: Abinaya R, Department of Pedodontics and Preventive Dentistry, Krishnadevaraya College of Dental Sciences, Bengaluru, Karnataka, India, e-mail: abinaya.raveendran93@gmail. com

How to cite this article: Abinaya R, Nagar P, Urs Pallavi, et al. Comparing the Efficacy of Three Minimally Invasive Techniques on Demineralized Dentin in Primary Teeth and Evaluating Its Residual Dentin and Microhardness Levels: An In Vitro Study. Int J Clin Pediatr Dent 2020;13(6):585-589.

Source of support: Nil

Conflict of interest: None

motor. These burs can remove soft carious dentin with ease but they blunt out when they contact with sound dentin. To achieve an effective removal of caries and to match hardness with sound teeth, an instrument made of a polymer that has Knoop Hardness Number (KHN 50) was devised. ${ }^{4}$

Atraumatic restorative technique is a minimal instrumentation technique to excavate of dental caries using hand instruments without using local anesthesia and restoring with GIC that chemically bonds to the tooth structure and also enhances remineralization by fluoride release. ${ }^{5}$ 
Considering, CMCR agents, a variety of them have been used since 1972, such as, GK-101, GK-101E, Caridex, Carisol gel, papacarie, and Carie-Care. ${ }^{1}$

Carie-Care's main active ingredient is from papaya extract-an endo protein. Also it has chloramines, dyes, and specific essential oils. They act by chlorination of partially degraded collagen. ${ }^{3}$

In this study, efficacy of bromelain, an extract derived from pineapple stem, is used as the CMCR agent. The term bromelain may refer to protease enzymes extracted from the plants of the family "Bromeliaceae". ${ }^{6}$ This bromelain is said to have anti-inflammatory, bactericidal, and bacteriostatic properties. ${ }^{7}$ Numerous studies reveal that bromelain has a potent deproteinization effect similar to that of papain, hence used for the study. ${ }^{8}$

My study aims to compare the caries removal efficacy of three minimally invasive techniques using the chemomechanical method-Bromelain gel, smart burs, and ART-and to analyze residual dentin under stereomicroscopy and dentin microhardness using Vickers hardness test.

\section{Materials and Methods}

\section{Preparation of the Sample}

The present in vitro study was conducted in the Department of Pedodontics and Preventive Dentistry, Krishnadevaraya College of Dental Science, Bengaluru. Thirty non-carious sound freshly extracted deciduous anteriors were selected for the study. Decoronation was done with sectioning bur. Acid-resistant nail varnish was applied to leave a window of $3 \times 3 \mathrm{~mm}$ on the proximal surface. The sample was demineralized using $(1.5 \mathrm{mM}$ calcium chloride, $0.9 \mathrm{mM}$ monopotassium phosphate, $150 \mathrm{mM}$ potassium chloride, and $0.1 \mathrm{mM}$ sodium acetate at $\mathrm{pH} 4.5$ ) and incubated at $37^{\circ} \mathrm{C}$ for 360 hours. $^{2}$ Demineralization was confirmed with RadioVisioGraphy (RVG).

\section{Preparation of Bromelain Gel ( $5 \mathrm{~mL}$ )}

For $5 \mathrm{~mL}$ preparation of bromelain gel, the following quantity of the components was mixed in a dappen dish, tested out on a dummy tooth for the cloudiness, and then carried on for the study.

- Bromelain powder-250 mg.

- Antioxidant (D-a tocopherol acetate) $-0.5 \mathrm{~mL}$.

- Humectant (glycerine) $-0.5 \mathrm{~mL}$.

- Thickener (carbopol)-200 mg in $2 \mathrm{~mL}$ distilled water.

- Emulsifier (amylopectin) - 50 mg in $1 \mathrm{~mL}$ distilled water.

- Preservative (propyl-p-hydroxybenzoate)-100 mg.

- Coloring agent (green apple).

- Distilled water as a vehicle-1 mL.

\section{Methodology}

Samples were longitudinally sectioned into two halves. One half of the sample was used in the study. Caries removal was carried out for a standard time of 2 minutes for all the groups: group I-Bromelain gel, group II-Smart bur, and group III-ART. The prepared sample was subjected to stereomicroscopic analysis and microhardness tests.

\section{Stereomicroscopic Analysis}

This analysis was carried out in the Department of Oral Pathology, KCDS. The treated and the untreated halves of each sample were focused under a stereomicroscope and their corresponding photographs were obtained. Later, these photographs were analyzed for the residual dentin thickness by comparing the total dentin thickness of a particular sample with the corresponding treated half of that sample. A software called Progress capture (version 2.0) was used in this study.

\section{Microhardness Evaluation}

The samples were tested for microhardness in the Central Manufacturing Technology Institute (CMTI), Bengaluru. Randomly five samples of each group were sectioned horizontally with a low-speed diamond cutter (Struers Minitom) and a dentin block was made under cool temperature. Finishing of the blocks was done with a polishing machine (Mektongripto 2v). The residual dentin hardness was calculated using CLEMEX (Hardness tester). The Vickers diamond indenter was enforced to the dentin surface at $50 \mathrm{~g}$ with a working time of 10 seconds was used for 5 indentations over the specimens of each group.

\section{Results}

The data obtained were tabulated and subjected to statistical analysis using the Statistical Package for Social Science (SPSS) for window version 18.5 (SPSS Inc., Chicago, Illinois, USA) software. One-way analyses of variance (ANOVAs) were used to test the difference between groups. To find out which of the two groups mean is significant difference post hoc test of Tukey test was used. In all the above tests, the " $p$ " value of $<0.05$ was accepted as indicating statistical significance.

The results were summarized as follows.

\section{Residual Dentin Thickness}

The difference in values between the treated and the untreated dentin was tabulated. The results revealed that the residual dentin thickness of group I ranged from 20.88 to $31.67 \mu$ m (mean \pm SD: $26.39 \pm 3.956)$ which is higher than group II: 15.67 to $23.65 \mu \mathrm{m}$ (mean \pm SD: $19.81 \pm 2.449$ ) and group III: 11.56 to $21.89 \mu \mathrm{m}$ (mean \pm SD: $16.06 \pm 3.454$ ) with a statistically significant $p$ value of $<0.001$ (Fig. 1 and Tables 1 and 2).

\section{Microhardness}

The results concluded that the VHN of the cavity floor prepared by bromelain gel ranged from 59.33 to $64.22 \mathrm{~kg} / \mathrm{mm}^{2}$ (mean \pm

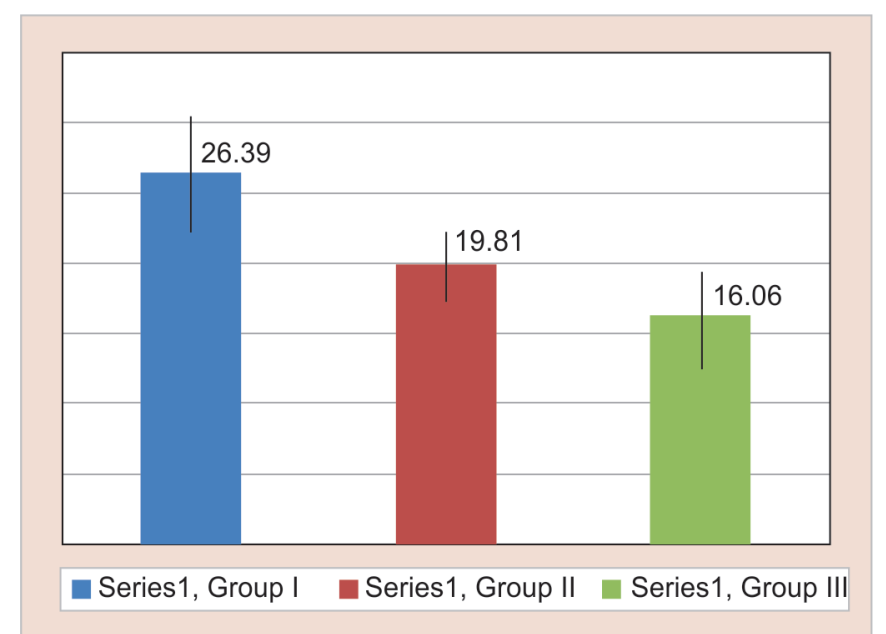

Fig. 1: Comparison of mean difference dentin thickness among the study groups 
Table 1: Residual dentin thickness: (difference in values)

\begin{tabular}{llllllll}
\hline & $N$ & Mean & SD & Min. & Max. & Fvalue & $p$ value \\
\hline Group I & 10 & 26.39 & 3.956 & 20.88 & 31.67 & 24.403 & $<0.001$ \\
Group II & 10 & 19.81 & 2.449 & 15.67 & 23.65 & & \\
Group III & 10 & 16.06 & 3.454 & 11.56 & 21.89 & & \\
\hline
\end{tabular}

*One-way ANOVA test

Table 2: Comparison between the groups using Tukey test

\begin{tabular}{lcc}
\hline & Mean diff. & p value \\
\hline Group I vs group II & 6.57 & $<0.001$ \\
Group I vs group III & 10.33 & $<0.001$ \\
Group II vs group III & 3.75 & 0.047 \\
\hline
\end{tabular}

SD: $62.18 \pm 1.88)$ which does not differ not statistically from the VHN of the sample prepared by ART that ranged from 55.54 to $72.03 \mathrm{~kg} / \mathrm{mm}^{2}$ (mean \pm SD: $62.93 \pm 6.630$ ), whereas the cavity floor prepared by smart burs ranged from 17.36 to $31.55 \mathrm{~kg} / \mathrm{mm}^{2}$ (mean \pm SD: $21.73 \pm 5.675$ ). The results indicated a statistically significant difference among the groups ( $p<0.001)$, especially between the groups I and II and groups II and 3 (Fig. 2 and Tables 3 and 4).

\section{Discussion}

Caries removal techniques are progressing more toward a biological and conservative direction. The minimally invasive dentistry techniques have become an area of interest in dental researches. This procedure provides judicious removal of carious dentin, so removal of healthy dentin is avoided which henceforth minimizes the need for local anesthesia during restorative procedures. ${ }^{9}$

This study was conducted to compare three minimally invasive techniques for caries removal using chemomechanical caries removal by bromelain gel and smart burs compared with ART caries removal.

In the literature, many studies have been done to compare the efficacy of one or more CMCR agents or one CMCR agent with other minimally invasive techniques. This study focuses on the comparison of CMCR agents using bromelain gel, smart burs, and ART. These three techniques were chosen because of their clinical precision, efficacy, and cost-effectiveness.

Minimally invasive treatment in dentistry dates back to early 1970s. The benefit for patients from MI lies in enhanced oral health through disease healing. ${ }^{10}$

The role of MID in pedodontics is huge. It is considered to be a boon for the uncooperative children because it tremendously decreases the fear or anxiety of getting the dental treatment done. These children have a greater fear of conventional rotary instruments due to their loud noise, vibration, and water spray, which is avoided in MID.

Commercially available CMCR agents are mostly papainbased, i.e., they are derivatives of papaya. It acts by disrupting the partially degraded collagen molecules, leading to the degeneration and eradication of the mantle fibers. This leads to a split of the polypeptide chains and hydrolyses the cross-links of collagen fibrils. After this, oxygen is freed, and this explains the appearance of bubbles on the surface and the blurring of the gel during the procedure. As papain can digest only the dead cells, carious tooth material only will be removed. Also, other advantages of

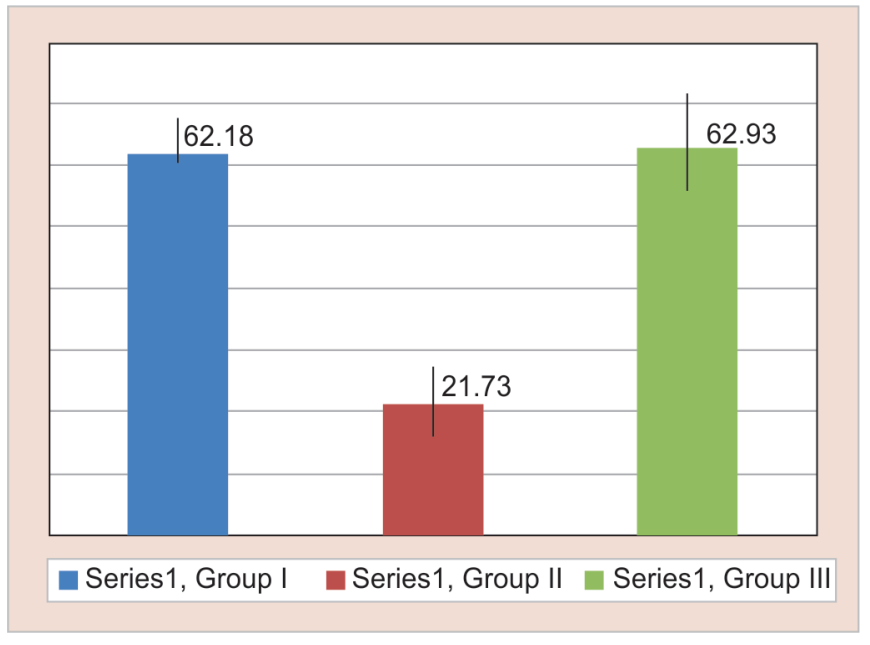

Fig. 2: Comparison of mean microhardness among the study groups

papain-based gel are the absence of smear layer formation and antibacterial nature. ${ }^{9}$

However, Bertassoni and Marshall ${ }^{11}$ have shown evidence that papain-based gel can degrade intact non-mineralized type I collagen fibrils.

Thus, the present study was conducted using bromelain gel. Bromelain is a derivative from stems of pineapple. The term bromelain may refer to the protease enzymes extracted from the plants of the family, "Bromeliaceae". Bromelain contains thiol endopeptidases and other components, such as, peroxidases, cellulases, phosphates, glucosidases, glycoproteins, and carbohydrates. Bromelain is stable at $\mathrm{pH} 3.0$ to $6.5^{12}$ and if it combines with its substrate, the activity is no longer susceptible to the $\mathrm{pH}$ effect.

Bromelain when applied topically helps in the removal of burnt debris and accelerates healing. ${ }^{13}$ It is said that bromelain activates collagenase in living tissue which then attacks the denatured collagen. ${ }^{7}$ This produces a distinction between living and dead tissue. Bromelain toxicity levels are very low with $\mathrm{LD}_{50}>10 \mathrm{~g} /$ $\mathrm{kg}$, and it has no carcinogenic potential. ${ }^{14}$ In addition to all the goodness, bromelain possesses anti-inflammatory and antibacterial properties.

Many studies in the literature about bromelain by Dayem and Tameesh, ${ }^{8}$ Chauhan et al., ${ }^{15}$ and Kocchar et al. ${ }^{16}$ stated that removal of unsupported collagen fiber with bromelain enzyme after acid etching resulted in improved bond strength and it significantly decreased the global leakage scores of the adhesive system.

Bromelain is a potent CMCR agent that has not been reported in the literature. However, due to the above-mentioned properties, this study was carried out with bromelain with CMCR agents.

In this study, bromelain gel was freshly prepared. The following ingredients were added to the commercially available pineapple powder. Alpha-D-tocopherol was added as an antioxidant that 
Comparing the Efficacy of Three Minimally Invasive Techniques on Demineralized Dentin in Primary Teeth

Table 3: Microhardness

\begin{tabular}{llllllll}
\hline & $N$ & Mean & SD & Min. & Max. & Fvalue $^{*}$ & $p$ value \\
\hline Group I & 5 & 62.18 & 1.888 & 59.33 & 64.22 & 104.531 & $<0.001$ \\
Group II & 5 & 21.73 & 5.675 & 17.36 & 31.55 & & \\
Group III & 5 & 62.93 & 6.630 & 55.54 & 72.03 & \\
\hline
\end{tabular}

*One-way ANOVA test

Table 4: Comparison between the groups using Tukey test

\begin{tabular}{lcr}
\hline & Mean diff & p value \\
\hline Group I vs group II & 40.45 & $<0.001$ \\
Group I vs group III & -0.75 & 0.972 \\
Group II vs group III & -41.20 & $<0.001$ \\
\hline
\end{tabular}

reduces the oxidative stress produced by the bacteria. Also, a humectant (glycerine), an emulsifier (amylopectin), a thickener Carbopol, and a coloring agent (green) were included. Propyl$p$-hydroxybenzoate was used as the preservative and distilled water as a vehicle. After that, the prepared sample was tested on a dummy tooth for checking the effervescence of the gel. A brisk effervescence was noted up to 30 seconds after which the gel was reapplied. There was no evident color blurring. The study was continued for 2 minutes as per methodology.

Polymer bur, it is a unique rotary instrument that is made from a medical-grade polyether-ketone-ketone. It is designed to selectively remove decayed dentine without cutting the healthy dentine, which the conventional burs do not do. This property is based on the hardness of the instrument is lower than the hardness of the healthy dentine. Also, this has the advantage of cutting fewer dentin tubules and thus, fewer pain sensations being triggered.

In this study, two parameters were checked: (1) Remaining dentin thickness after the carious dentine removal and (2) Vickers microhardness test of the dentine.

A remaining dentin thickness of approximately $2 \mathrm{~mm}$ of dentin or an equivalent thickness of restorative material is essential to protect the pulp. ${ }^{17}$ In the literature, many studies have proved to have a significant difference in the residual dentin thickness when caries removal was done using conventional and chemomechanical ways. An in vitro study was conducted in 2007 by Fernanda ${ }^{18}$ evaluating the residual dentin after conventional and chemomechanical caries removal using SEM. He concluded that though there was similar tag formation in both groups, there was a difference between dentin treated with rotatory instruments and that treated with chemomechanical methods. The rotary group showed a smooth and uniform surface with a typical smear layer and exposed dentinal tubules. The CMCR group specimens revealed an irregular surface with the presence of an anamorphic layer and bacteria on the dentinal surface. On the contrary, in this research, caries removal using bromelain gel was found to be superior when compared to other groups which were evident in the stereomicroscopic evaluation; the characteristic difference in the treated and the untreated dentin thickness was observed.

Quasim and Sullaiman ${ }^{19}$ in an in vitro study concluded that Carisolv $^{\mathrm{TM}}$ gel does not alter the microhardness of sound dentin. Previous microhardness studies by Hossain et al. ${ }^{20}$ and Corrêa et al. ${ }^{21}$ stated that there is no difference in microhardness after caries removal between CMCR and rotatory groups when tested in permanent and primary teeth. Garcia-Contreras et al. ${ }^{2}$ did a comparative study on the efficacy of conventional burs and
Carisolv and concluded that the chemomechanical system is effective for caries elimination and their remaining composition and microhardness are similar to healthy dentin. In the present study also, Vickers microhardness for ART removal was $62.93 \mathrm{VHN}_{i}$ chemomechanical caries removal was $62.18 \mathrm{VHN}$, which is similar to values of healthy dentin. Similar values of remaining dentin of the mineralized tissues were obtained between the bromelain gel and the healthy dentin, and this concludes the chemomechanical system may be an effective option.

Limitations of this study could be an insufficient sample size. So, further research has to be performed to compare the clinical efficacy, smear layer removal, and better marginal adaptation of restoration when treated with these groups, particularly using bromelain gel.

\section{ConCLUSION}

The stereomicroscopic analysis revealed bromelain gel and smart burs to be superior to ART. Also, bromelain gel was found to have comparable microhardness levels as that of healthy dentin.

In terms of caries removal and microhardness, bromelain gel was highly efficient when compared to other procedures.

Bromelain, therefore, can be considered as an effective chemomechanical caries removal agent.

\section{Clinical Significance}

Fear and anxiety of children and parents about conventional drills led to the emerging trends of minimally invasive restorative dentistry. This research indicated the use of bromelain gel and smart bur in the process of caries removal and that bromelain was more efficient when compared to other groups.

\section{References}

1. Anwar AS, Kumar RK, Prasad Rao VA, et al. Evaluation of microhardness of residual dentin in primary molars following caries removal with conventional and chemomechanical techniques: an in vitro study. J Pharm Bioall Sci 2017;9(5):S166-S172. DOI: 10.4103/jpbs.JPBS_148_17.

2. Garcia-Contreras R, Scougall-Vilchis RJ, Contreras-Bulnes R, et al. A comparative in vitro efficacy of conventional rotatory and chemomechanical caries removal: influence on cariogenic flora, microhardness, and residual composition. J Conserv Dent 2014;17(6):536-540. DOI: 10.4103/0972-0707.144588.

3. Jain $P$, Kaul $R$, Saha $S$, et al. Smart materials making pediatric dentistry bio-smart. Int J Pedod Rehabil 2017;2(2):55-59. DOI: 10.4103/ijpr. ijpr_8_17.

4. Khijmatgar S, Balagopal S. Minimally invasive dentistry: polymer burs J Dent Oral Biol 2016;1(2):1009.

5. Kumar KS, Prasad MG, Sandeep RV, et al. Chemomechanical caries removal method versus mechanical caries removal methods in clinical and community-based setting: a comparative in vivo study. Eur J Dent 2016;10(03):386-391. DOI: 10.4103/1305-7456.184151.

6. Heiniche RM, Gortner. WA. Stem bromelain - a new protease preparation from pineapple plants. Econ Bot 1957;11(3):225-234. DOI: 10.1007/BF02860437. 
7. Kelly GS, Bromelain ND. A literature review and discussion of its therapeutic applications. Alt Med Rev 1996;1(4):243-257.

8. Dayem RN, Tameesh MA. A new concept in hybridization: bromelain enzyme for deproteinizing dentin before application of adhesive system. Contemp Clin Dent 2013;4(4):421-426. DOI: 10.4103/0976237X.123015.

9. Mohamed Rehab SK. Clinical evaluation of papacarie in primary teeth. J Clin Pediatr Dent 2009;34(2):117-124. DOI: 10.17796/jcpd.34.2.f312 p36g18463716.

10. Kumar RG. Minimally invasive dentistry - a review. Int J Clin Prev Dent 2013;9(2):109-120.

11. Bertassoni LE, Marshall GW. Papain-gel degrades intact nonmineralized type I collagen fibrils. NIH public access. Scanning 2009;31(6):253-258. DOI: 10.1002/sca.20171.

12. Murachi $\mathrm{T}$, Neuratii $\mathrm{H}$. Fractionation and specificity studies on stem bromelain. J Bio Chem 1960;235(1):99-107.

13. Houck JC, Chang CM, Klein G. Isolation of an effective debridement agent from the stems of pineapple plants. Int J Tissue Reacts 1983;5:125-134.

14. Tausigg SJ, Yokoyama MM, Chinen N, et al. Bromelain - a proteolytic enzyme and its clinical application. Hir J Med Sci 1975;24:185-193.
15. Chauhan K, Basavanna RS, Shivanna V. Effect of bromelain enzyme for dentin deproteinization on bond strength of adhesive system. J Conserv Dent 2015;18(5):360-363. DOI: 10.4103/0972-0707.164029.

16. Kocchar R, Dewan R, et al. Comparative evaluation of shear bond strength of resin bonded dentin with and without dentin deproteinization. IOSR J Dent Med Sci 2018;17(3):74-77.

17. Tomer AK, Miglani A. Residual dentine thickness. Int J Appl Dent Sci 2016;2(4):96-99.

18. Fernanda NP. Evaluation of residual dentin after conventional and chemomechanical caries removal using SEM. J Clin Pediatr Dent 2007;32(2):115-120. DOI: 10.17796/jcpd.32.2.44n2787118133880.

19. Quasim AS, Sullaiman AA. Evaluation of chemomechanical caries removal $\left(\right.$ Carisolv $\left.^{\mathrm{TM}}\right)$ using the Vickers hardness test - "An in vitro study". J Minim Interv Dent 2008;1(2):113-125.

20. Hossain M, Nakamura Y, Tamaki Y, et al. Dentinal composition and Koop hardness measurements of cavity floor following carious dentin removal with Carisolv. Oper Dent 2003;28:346-351.

21. Corrêa FN, Rocha Rde O, Rodrigues Filho LE, et al. Chemical versus conventional caries removal techniques in primary teeth: a microhardness study. J Clin Pediatr Dent 2007;31(3):187-192. DOI: 10.17796/jcpd.31.3.1440852707v3g1u0. 